\title{
VIOLÊNCIAS PRIVADAS COMO SE FOSSEM DIREITOS PÚBLICOS. PERSPECTIVAS ANTROPOLÓGICAS
}

Susana Durão

Na última década assistimos a um aglomerado de acções políticas com fins judiciais sobre conflitos considerados moralmente intoleráveis. Foi constituída uma verdadeira cruzada contra o que se convencionou chamar de violência doméstica (VD). Assisti a esse processo em Portugal e acompanhei-o de perto. Hoje temos elementos suficientes para defender que fenómenos como a violência, com vitimização e consequente tratamento policial e judicial, são, salvo raras excepções, perspectivados através de uma ótica que combina punição e reparação. É nesta perspectiva dual que têm surgido as análises mais recorrentes. Em geral, lamenta-se uma certa economia moral da punição entre polícias, que punem uns em detrimento de outros; uma justiça que chega tarde e se revela insuficiente. ${ }^{1}$

As posições analíticas reificam o que foi identificado por dois autores franceses como o "tempo das vítimas" (Eliacheff \& Lavière 2007), no qual a figura da vítima parece ter ocupado o lugar do herói moderno, tornando-se a última expressão do elo e da reparação social. Mas a questão é tão complexa que alguns antropólogos têm ajudado a deslindar o problema submetendo-o a leituras etnográficas. Em contextos nacionais e serviços emergenciais, a ideia de vítima tende geralmente a ser política e socialmente construída, tendo por base certos marcadores de sexo e estatuto. É o caso do Serviço Único de Saúde no Brasil que criou as suas políticas públicas de atuação concebendo a vítima como mulher. De acordo com autores como Cynthia Sarti (2009), isto não só mascara realidades sociais mais amplas, como evita que qualquer um possa reclamar para si o estatuto de vítima e consequente atendimento, nomeadamente jovens e negros, cuja vitimização é estatisticamente representativa.

Apesar dos diferentes ângulos de análise, hoje podemos dizer que todos, incluindo os cientistas sociais, se manifestam unanimemente intolerantes e contra a violência dirigida a pessoas e, particularmente, contra cônjuges ou parentes. Não por acaso, um pouco por todo o mundo, a resposta legal 
tem surgido num sentido: criminalizar o fato. Portugal não é excepção. A Lei n. ${ }^{\circ} 7 / 2000$ introduz o regime legal substantivo e processual da VD, mas só com a Lei n. ${ }^{\circ}$ 59/2007 é que o fenómeno da agressão com violência expressa entre familiares passa a ser considerado crime público. Ou seja, nesse momento, por força de lei, a ativação do procedimento criminal deixa de depender da vontade e da iniciativa das vítimas, o que, em tese, amplia o poder de intervenção direta dos agentes policiais e a acção da justiça no "policiamento das famílias", como diria Donzelot (2005).

Coincidentemente, ao longo dos últimos anos, o "combate" a este crime foi considerado uma prioridade na política nacional. Foram criados grandes planos políticos, mas também medidas concretas de protecção da vítima. Entre estas figurou o alargamento da previsão de indemnização para as vítimas de crimes violentos às vítimas de VD; a oferta nas delegacias de um documento oficial que garante o "estatuto de vítima", com acesso gratuito e emergencial em vários serviços do Estado; e a previsão de detenção policial do agressor, fora do flagrante delito, quando legitimado a priori, pelo grau de risco, e a posteriori, justificado nos chamados autos policiais. A esse processo aliaram-se fortíssimas campanhas mediáticas, transmitindo e fortalecendo uma ideia: todos somos moralmente responsáveis perante violências privadas. É preciso não hesitar e partir para a sua denúncia, reforçando os movimentos por direitos públicos.

É preciso dizer que a lei portuguesa foi gerada tendo como objectivo a regulação de relações amorosas ou análogas, percorrendo todas as gerações. Dessa legislação foi propositalmente retirado o referencial direto ao género, ao contrário do que aconteceu com as propostas das leis brasileira e espanhola, para dar apenas dois exemplos. Se em Espanha a VD vem a reboque da violência de género, contra a mulher, esta sim considerada estrutural, no país vizinho o enfoque centrou-se na família e nas violências privadas que afetam relacionamentos conjugais transgeracionais. A violência familiar contra idosos foi um dos temas abrangidos pela actual lei, em um dos países demograficamente mais envelhecidos da Europa.

É possível ensaiar algumas explicações para este foco político-jurídico no referido país. Por um lado, uma certa tradição pós-ditatorial alicerçada em ideais de universalidade de direitos cidadãos perante a lei. No contexto da União Europeia está hoje difundida a noção de que os direitos universais são mais dignos do que os direitos de comunidades ou grupos sociais. Nesse sentido, os movimentos reformistas penais em Portugal têm sido envergados por dentro de sectores do Estado, da Justiça e dos profissionais do Direito, e menos por intermédio de movimentos feministas organizados. Ainda assim, algumas discussões feministas tiveram um papel atuante até 
meados de 2000. Na política, surgiu a CIG (Comissão para a Cidadania e Igualdade de Género) com várias medidas; na mobilização por mais justiça foi criado o Projecto Penélope, em 2003, promovido pela APAV (Associação de Proteção à Vítima), que visava criar acções preventivas para combater a violência exercida contra crianças, jovens e mulheres ao sul da Europa. Em simultâneo, nas Polícias, surgiam os Programas INOVAR e o "Verão Azul", criando salas de atendimento a vítimas nas delegacias e a sensibilização para o recrutamento de mulheres nas forças policiais. Porém, nada disso foi suficiente para fazer estremecer o consenso de que a lei de VD não se reduziria, mas antes incluiria a violência de género e as agressões dirigidas a mulheres. ${ }^{2}$ Entretanto, a caminho do fim da década, um outro tema entra na agenda e nos planos de justiça nacional e transnacional: o tráfico de seres humanos. Esta discussão parece ter interrompido o que poderia ter sido uma reflexão e um debate social mais amplo em torno de alguns anos de experiência volvidos sobre políticas interventivas e a nova lei de VD no país.

Certo é que os sujeitos declarados judicialmente vítimas se mantiveram dominantemente mulheres (entre os 25 e os 45 anos, quase $90 \%$ ) e os agressores denunciados, homens (DGAI 2010, 2011). Associações como o Observatório de Mulheres Assassinadas da UMAR (União de Mulheres Alternativa e Resposta) têm demonstrado a dimensão do problema. Em 2012, em um país com 10 milhões e 500 mil habitantes, foram identificados 36 casos de mulheres assassinadas e 49 tentativas de homicídio, práticas levadas a cabo por companheiros ou ex-companheiros das mulheres atingidas.

Vale a pena introduzir aqui uma nota de contexto. Em Portugal, talvez em conformidade com o tom universalista da referida lei, não foi criado nada que se assemelhasse a delegacias de atendimento ou defesa da mulher. Pelo contrário, como o nome indica, as esquadras genéricas são unidades de atendimento de todo e qualquer tipo de delito. ${ }^{3}$ Ali, tanto homens como mulheres, mas muito mais homens, fazem a patrulha e o atendimento a qualquer tipo de cidadão, envolvido em qualquer tipo de delito ou ilícito, incluindo sujeitos que se dirijam às delegacias denunciando maus-tratos. Em quase todas as delegacias existem equipes (em geral de dois agentes) que são mais especializadas na prevenção da VD, as designadas equipas de apoio a vítimas (EPAV). É frequente existir a preocupação de integrar agentes femininas nas EPAV, mas o seu reduzido número de efectivos nem sempre o permite. Embora com algum esforço nacional de propagação do chamado policiamento de proximidade, estas equipes mantêm-se periféricas no trabalho das delegacias e muito reduzidas no conjunto do policiamento (Durão 2012). Nesse sentido, todo o trabalho "a quente" acaba sendo conduzido pelos patrulheiros e seus chefes diretos, com escassa formação para tratar com os temas da vitimização. ${ }^{4}$ 


\section{Indiferenças e impotências}

Como referi, as análises deste fenómeno em Portugal tendem a passar pelo par punição/reparação. Estas deixam de fora manifestações e sentimentos socialmente partilhados, necessariamente mais ambíguos, e que apontam para lógicas de indiferença e impotência presentes nas relações mantidas entre os queixosos e os agentes da justiça, desde logo, os policiais. Foi na perspectiva de conduzir a discussão para dimensões antropológicas mais amplas da questão que criei e coordenei um projeto de pesquisa sobre este tema. ${ }^{5}$ Com a ajuda dos membros da equipa de pesquisa, resolvi focar a atenção nas dimensões intersubjectivas do real. Considerei que o que se passa entre os envolvidos no ato de uma chamada, denúncia e ocorrência policial, em atos jurídica e burocraticamente enquadrados como são esses, merece o nosso escrutínio etnográfico.

É preciso explicitar que a noção de intersubjectividade tem uma longa discussão iniciada com a filosofia fenomenológica de Edmund Husserl. Antropólogos como Mickael Jackson e Alessandro Duranti têm proposto que se recupere o estudo das intersubjectividades humanas na antropologia. ${ }^{6}$ Entendo esta como uma dimensão constitutiva da socialidade entre sujeitos, incluindo acções de segurança e justiça.

Num primeiro momento, podemos sublinhar dois aspectos da comunicação humana desenvolvidos pelos autores: i)A noção de que na acção humana está sempre concebida a possibilidade da "troca de lugares". O mundo é vivenciado como algo comum, onde cada um pode participar nas acções e nos sentimentos do outro sem se tornar o outro, através de um entendimento empático. ii) A dimensão existencialista da intersubjectividade contém um elemento político, aquilo que fornece o sentido da integridade existencial. Jackson recupera a noção de vita activa de Hannah Arendt quando esta defende: “Todos os aspectos da condição humana têm alguma relação com a política; mas esta pluralidade é especificamente a condição [...] de toda a vida política" (Arendt 1991:15). Dito de outro modo, na perspectiva de Arendt, não há condição existencial sem a dimensão política, aquela que aufere à vida a acção. Desse modo, ela propõe uma filosofia política que contemple o labor, o trabalho e a acção - elementos essenciais que devem integrar a vita contemplativa que dominou o pensamento metafísico clássico. Nesse sentido, a violência, ocorrida nas práticas intersubjetivas, quebra a possibilidade de ação.

Embora o corpus de saberes do Direito possa existir em abstracto, este concretiza-se e é ressignificado em atos e práticas intersubjetivos. No âmbito dos encontros e por intermédio da ação, policiais e denunciantes "trocam de lugar", mas é por intermédio da análise etnográfica que melhor podemos conhecer os modos dessa troca intersubjectiva. Lembre-se que já Malinowski 
em seu famoso livro Crime e costume na sociedade selvagem (2003) duvidava da lei como um conjunto de regras impostas por uma autoridade independente de laços pessoais. Embora a sua solução teórica fosse pouco satisfatória - o estudo das "forças" que tornam obrigatórias as convenções, os incentivos psicológicos e sociais complexos da "jurisprudência primitiva" — vale a pena reter a ideia de que mesmo em serviços administrados pelo Estado, as trocas intersubjectivas medeiam todo e qualquer tipo de entendimento. Creio que podemos então falar da "socialidade" da acção policial e jurídica, não no sentido do que conecta positivamente os sujeitos entre si ou como sinónimo de experiência compartilhada, mas no acto do "fazer social", ou dito de outro modo, como parte do processo intersubjetivamente constituído da vida social, como veio a ser definido por Marylin Strathern (2007).

É preciso sistematizar melhor a dupla acepção de socialidade que adopto neste texto. Recentemente, propostas de teorias da socialidade em antropologia têm alargado a noção para além do seu entendimento mais comum e fundador - a afectividade e a relacionalidade - envolvendo também dimensões éticas e políticas da acção de vida colectiva. A socialidade foi originalmente concebida como uma matriz dinâmica de relações na qual os sujeitos estão constantemente interagindo de modo coprodutivo, mas continuamente plástico e maleável. A discussão remonta a um debate epistemológico e à defesa acesa desta ideia por Strathern e Toren que desejavam acabar de uma vez por todas com a vaga noção de sociedade (cf. Ingold 1989). Numa linha complementar, antropólogos e filósofos, como Moore, Bersani, Long e outros, têm defendido que uma tal matriz vai além da dimensão ontológica ou teórica aportada pelas autoras e que contém dimensões coconstitutivas da política, da ética e da imaginação (cf. Long \& Moore 2013).

Submetendo a pesquisa etnográfica a uma tal matriz teórica, pretendo desenvolver nas seguintes seções um argumento. Entre os sujeitos em acçãoagentes de autoridade e mulheres que os procuram para sua segurança em casos de violência - há uma coconstituição de si que passa por direitos e freios, isto é, por práticas impotentes partilhadas. Estas apenas são impotentes porque são moralizadas, por todos, nessa intersubjectividade coprodutiva, como se fossem incompletas, embora de modo diferente e até contraditório, como se verá.

\section{Etnografando dimensões intersubjectivas}

Para seguir com uma tal abordagem teórica, eu teria de a complementar com uma escolha metodológica. Foi necessário tornar a intersubjectividade, 
essa potencialidade para a troca de lugares e a vita activa - no caso, entre os sujeitos declarados vítimas e os agentes da autoridade - dinâmicas observáveis, etnografáveis. Não se tratava apenas de observar encontros entre sujeitos e a interactividade enquanto fenómeno microssocial. Interessava apreender as expressões intersubjectivas e morais proporcionadas por esses encontros sobre os quais impera algum tipo de expectativa.

Foi assim que a antropóloga e o criminólogo do projeto decidiram partir para o trabalho de campo, durante 10 meses, em quatro delegacias onde o volume de denúncias por VD era expressivo, situadas nas maiores regiões metropolitanas do país, Lisboa e Porto. Importava observar e participar nos encontros entre agentes policiais e mulheres que se apresentavam ou eram definidas juridicamente como vítimas, mas também toda a dimensão mundana do trabalho policial. Como bem diz Arendt: "A condição humana do trabalho é a mundanidade" (Arendt 1991:15).

Situei também o olhar num conjunto de vários anos de autos policiais (registados como VD). Aproveitei para introduzir uma inovação metodológica neste campo de estudos: solicitando a agentes e chefes de polícia (homens e mulheres) que escrevessem os seus diários de trabalho. Destes resultaram dois documentos muito ricos - o diário de um chefe e o de uma agente de polícia, a trabalhar em duas delegacias diferentes.

\section{Por que acrescentar a dimensão da moral?}

Em todo este conjunto reflexivo há um problema de ordem epistemológica que entra em cena, problema este que a maioria de nós, antropólogos, enfrenta nos nossos objectos de pesquisa contemporâneos. Nos encontros da pesquisa, em campo, não estamos apenas "nós" e "eles"ou os vários "nós" e os vários "eles" que servem os nossos atlas teóricos e comparações etnográficas. Não somos apenas a presença física de corpos, mutuamente constitutivos, com percepções interpessoais de um mundo objectivo.

Antropólogas brasileiras como Manuela Carneiro da Cunha (2009), Eunice Durham (2004) e tantos outros que de modo diferente anteciparam algo que julgo ser da maior relevância: observador e observados não são os únicos conjuntos coconstitutivos dessa intersubjectividade em presença que irá ser traduzida pelos antropólogos - em interpretação de sentidos (como diria Evans-Pritchard nos últimos textos, 1962), em redes de significados (como defendeu Geertz 1989), em alegoria etnográfica (para citar Clifford apud Gonçalves 2011), ou na agora reclamada teoria etnográfica (Nader 2011) - isto é, não somos os únicos detentores originais e participantes do 
ato de conhecer, como pareciam crer os microssociólogos e os interaccionistas simbólicos. Todos estamos atravessados por décadas de políticas públicas, práticas de reflexão pública (incluindo as de antropólogos) que, de uma maneira ou de outra, têm sido impressas por idiomas dos direitos humanos, activando julgamentos e intencionalidades em cada um de nós - a política da vita activa (Arendt 1991). ${ }^{7}$

Johannes Fabian defendeu algo que o aproximou das assunções de Husserl ao dizer: "Nas investigações antropológicas, a objectividade não reside nem na consistência lógica de uma teoria nem é apenas dada pelos dados do campo, mas funda-se sim na intersubjectividade humana" (Fabian 1971:25). Impossível não concordar com ele. Porém, o que defendo aqui é que, embora a intersubjectividade, como fenómeno humano, seja a pré-condição da interacção e o ingrediente base da antropologia, nela se justapõem morais relacionais, sobretudo quando envolvemos em nossas pesquisas o trabalho que certas instituições fazem com certos sujeitos e vice-versa, o que certos sujeitos fazem com e em instituições. ${ }^{8}$

A moralidade, entendida como modalidade culturalmente relativa e diversa, tem sido recentemente explorada na antropologia (Zigon 2008). Não é este o caminho de meu argumento neste texto. Pretendo antes demonstrar como certas expectativas, presentes em encontros institucionalizados, não têm apenas o sentido de uma economia subjetiva, que seria emitida do cidadão para o servidor público, isto é, como uma exigência incondicional por direitos. Ou, em sentido inverso, nas ambiguidades destes operadores da segurança, em interacção com suas clientes. As expectativas que aqui trato se baseiam numa série de conceções intersubjectivas que, sendo morais, conectam pessoas e serviços antes, durante e depois dos encontros, morais estas que são condicionadas por previsões do que poderia ser e por vezes do que deveria ser a resposta policial e da justiça. Ou seja, a intersubjectividade produzida em encontros entre policiais e vítimas de violência doméstica é atravessada por considerações práticas que a delimitam a todo o momento.

\section{Gramática da impotência}

Nesse sentido, procurei saber como e em que profundidade os agentes policiais participam dessa troca intersubjetiva que os leva a ter uma visão condicionada pelas visões que os outros têm do seu trabalho e, portanto, $a$ favor de um outro - pessoas agredidas que pedem a um elemento externo para ser socorridas. No decurso de um tal questionamento, deparei com 
o que pode ser designado como uma transversalidade da gramática da impotência - definida como uma espécie de linguagem moral que deriva da troca intersubjectiva em situações de encontro e de intervenção, entre sujeitos definidos como vítimas e agentes.

Todos os envolvidos com quem contactei no projeto se manifestaram, de modo variável, impotentes. Dados do campo revelaram a perpetuação subtil da vulnerabilização dos queixosos (no caso, queixosas) após o apelo feito aos agentes. Mas não só, também revelaram a subtil fragilidade do trabalho policial.

Quando em ato de atendimento ou noutras situações cotidianas, os agentes repetiram muitas vezes uma frase: "A violência doméstica é dos crimes mais complicados para os policiais". Com o tempo compreendi que esta "complicação" não residia apenas nas situações que tinham enfrentado ou que previam vir a enfrentar, já de si no cruzamento de dimensões públicas e privadas da vida, envolvendo esse todo impenetrável que na ótica policial são as relações familiares. A complicação encontrava-se também na forma como os agentes previam não estar preparados (institucional e pessoalmente) para policiar este fenómeno que, entretanto, se tornara crime público. Ou seja, os encontros de VD aos quais os agentes eram chamados a intervir revelavam-se duplamente complicados - no sentido operacional e no sentido emocional. Certos freios intersubjectivos eram assim accionados e eles mereciam ser entendidos. Defino estes travões como recuos sistemáticos e previsíveis na autoridade policial quando se espera que esta se faça representar pelos denominados "agentes da autoridade".

Trilhando falas e gestos, o trabalho de campo foi, a maior parte do caminho, um registo denso da forma como se conduz um certo estilo de policiamento. E a este estilo chamei os mínimos burocráticos. Isto porque os encontros entre agentes e vítimas desencadeavam em geral um roteiro com escassas variações burocráticas. Ao chegarem ao local da denúncia, os agentes começavam por separar fisicamente os dois "elementos" em conflito (mesmo se este tivesse cessado). A preocupação primeira passava por anotar as identificações pessoais. Em caso de pedido ou de decisão pessoal, os agentes facultavam o já referido documento, o "estatuto da vítima". Em verificando sinais de agressão, os policiais conduziam então os sujeitos agredidos aos serviços médicos para averiguação e, muito mais raramente, a abrigos e serviços de assistência social emergenciais.

A maior parte das vezes o processo dividia-se em dois momentos: a acção burocrática in loco e a condução do processo administrativo do auto policial já na delegacia e sem a presença dos envolvidos no litígio. Não verifiquei grande diferença no atendimento conduzido directamente nas 
delegacias, quando estes serviços eram acionados pelas queixosas que para ali se dirigiam. Talvez o pormenor mais importante fosse exactamente o de que este momento poderia facultar mais trocas intersubjectivas, pois envolvia a atingida na condução do seu próprio caso no registro policial. Todavia, também neste meio de atendimento estavam implicados subtis silenciamentos. Raramente os agentes e os chefes requeriam das queixosas a sua participação ou sequer consideravam o seu sofrimento. Uma segmentação de campos para preencher, software que se aprende a custo e toda uma sorte de documentação e dificuldades informáticas distraíam os agentes da comunicação com as mulheres que chegavam às delegacias com pedidos de socorro, com quem estes, muitas vezes, mal cruzavam o olhar, de tão absorvidos que estavam nas lides burocráticas.

Embora tendo sido criadas as designadas "salas de atendimento a vítimas" nas delegacias, estas eram raramente usadas para o efeito, tendose tornado, por inércia da vida policial, salas multiuso. Ou seja, a medida que teve lugar no já referido projeto INOVAR, pela mão de activistas como Rosmaninho, não alcançou o impacto organizacional que almejava. Registrámos assim, em cada um de nossos cadernos de campo, vários momentos da arte policial de pouco intervir nas cenas de VD e os contatos superficiais e elusivos dos policiais com as vítimas. Ofereço uma descrição que ilustra o que acabo de dizer. Trata-se de notas de campo em uma delegacia ao norte do país. Esta é uma amostra de situações típicas a que fomos assistindo no decurso da pesquisa, revelando os entraves intersubjectivos traduzidos numa atuação policial pelos mínimos burocráticos.

Num sábado ao final da tarde, na delegacia local, receberam uma chamada a dar notícia de uma situação de VD pela voz de um vizinho. Como era hábito, nós, pesquisadores, acompanhámos os dois patrulheiros ao local da chamada, inicialmente em direção à casa do referido vizinho, o emissor da denúncia.

Na primeira interpelação, o vizinho, com cerca de 60 anos, comentou com os agentes que as agressões entre o casal ocorriam há anos e que o senhor batia frequentemente na mulher. Referiu que naquele dia as agressões tinham sido especialmente violentas. O agressor teria usado um cabo de vassoura com o qual batia incessantemente na mulher. $\mathrm{O}$ vizinho tudo presenciara porque a cena teria ocorrido no jardim da casa.

Depois de ouvir, sem registo ou reação, os agentes (ambos homens, um com cerca de 30 anos e o outro 40) seguiram até a casa do referido casal. A senhora estava no jardim. Era uma idosa com cerca de 80 anos de idade. Estava visivelmente agredida, vestindo um pijama, várias camisolas e um casaco. No tecido das calças viam-se manchas molhadas de sangue. Tinha 
alguns arranhões no rosto e um deles percorria boa parte da face esquerda. Numa das mãos tinha também um grande ferimento, em carne viva, disfarçado por um band-aid.

Em conversa com os agentes a idosa admitiu, com certa naturalidade, ter sido agredida pelo marido. E onde estava o mesmo? No quarto, no interior da casa. Os agentes gritaram por ele, convidando o também octagenário a descer ao jardim. Como não foram atendidos, resolveram entrar.

A casa tinha um forte odor a urina e a humidade. O idoso encontrava-se na cama. Estaria doente e a recuperar de uma cirurgia aos intestinos. Assim que os agentes começaram a fazer perguntas, o mesmo admitiu ter batido na esposa. Disse que sabia que não o deveria ter feito, mas que era mais forte que ele. Levantando o tom da voz, saiu em sua defesa, dizendo que a mulher não andava "boa da cabeça", que era "manhosa", não cuidava da casa e "mijava" a cama de noite - e que tudo isso o enervava. Os agentes repreenderam-no verbalmente. Disseram que aquilo não poderia continuar e que agora ele corria o risco de "ter problemas com a justiça". Os agentes recolheram os dados de identificação. Sem mais. (Ficaram igualmente a saber que a filha do casal, com cerca de 40 anos, divorciada, vivia na casa ao lado). Assim como entraram, os agentes partiram, discretamente.

Toda a redacção do auto foi feita na delegacia. Mais tarde, quando os agentes voltaram para recolher a assinatura da idosa sobre os autos, trouxeram consigo o documento de atribuição do "estatuto da vítima" e a notificação da mesma para o exame médico no Instituto Nacional de Medicina Legal. Na ocasião, a filha do casal interpelou-os. Esta referiu que também ela fora vítima de VD, agredida pelo ex-marido durante vinte e cinco anos, até o dia em que fez uma denúncia na justiça. Entretanto, o marido fugiu do país, mas dizia viver em pânico, com medo que ele regressasse.

Um momento antes de saírem de cena, pela segunda vez, os agentes foram interpelados por um segundo vizinho. Este referiu que o que ali se passava era uma "pouca-vergonha", que a senhora era agredida há anos e que ninguém fazia nada. E sentenciou: "Será preciso que ele a mate?". O mesmo referiu redes vicinais. Muitos ali se organizavam para ajudar a "pobre senhora", ofertando roupas, comida e cobertores... A informação não foi usada pelos agentes.

No regresso à delegacia, como era usual, os agentes comentaram connosco, no carro-patrulha, que aquilo era uma situação "complicada" e que era muito mais uma situação "social" do que propriamente "criminal". Repetiram os lamentos que ouvimos centenas de vezes: Nada mais poderiam fazer... (Diários de Campo numa Delegacia ao Norte de Portugal, Santo Tirso, Concelho do Porto; Outubro de 2011). 
Esta situação poderia ser analisada sob vários ângulos. Mas a questão que mais interessa discutir, tendo por enfoque o problema teórico apresentado, é como, apesar de apenas desencadearem os mínimos burocráticos, em situações que até submetidas ao olhar de leigos parecem requerer mais do que isso, os agentes não operam sem lamento moral. Considero estes atos burocráticos mínimos na medida em que eles revelam exatamente um envolvimento diminuto na resolução imediata da ocorrência. O registro burocrático simplificado é apenas uma parcela muito reduzida de tudo o que pode ser contido numa operação policial deste género, podendo ter repercussões negativas para a fase, posterior, da investigação criminal (Durão \& Darck 2013). Todavia, há que ressaltar, os policiais associam à sua impotência - expressa na contundente afirmação "não podemos fazer mais nada" - algum tipo de avaliação que indica que sabem que deles é esperado algo mais, precisamente aquilo que defendem não poder ativar. Travam na acção, mas logo justificam.

Michael Herzfeld tem defendido que os limites das burocracias e dos burocratas "modernos" estão baseados num idioma da autoexoneração, isto é, na retirada e mesmo na libertação da obrigação e do dever associados ao cargo que assumem. O autor analisa os seus dados etnográficos do contexto grego e sul-europeu nos termos de uma teodiceia secular que caracterizaria as burocracias público-estatais. O meu argumento e os meus dados etnográficos desafiam a ideia de que estamos perante uma "produção social da indiferença", cunhada por Herzfeld (1992), uma vez que explicito e analiso outros tipos de consequências e desdobramentos incitados pela impotência - diferente de indiferença moral - de agentes públicos, no caso, policiais. Parte substancial do argumento tem a ver com o fato de eles não estarem sozinhos quando o fazem, mas de as suas impotências atravessarem também as subjetividades daquelas que reclamam para si o estatuto de vítimas de violências privadas.

A ideia que defendo é a de que nos encontros intersubjectivos, nestes e nos demais, os agentes são constantemente chamados a colocar-se no lugar do outro, sobretudo quando se trata da faceta de "defesa" de alguém, mas fazem-no defendendo-se a si mesmos e afirmando não poderem desencadear a ajuda profissional esperada. Alegam frequentemente que não são autorizados a fazê-lo pelos seus superiores, pelos oficiais da justiça. Como muitos nos referiram: "Nós não somos juízes; nós apenas informamos aos juízes". Este torna-se assim um poderoso gerador de impotências.

Em boa medida, há um recurso ao passado para justificar o presente. Muitos agentes e chefes defendem que "os mais velhos" - numa categoria indefinida que tende a agrupar agentes e chefes que entraram para o serviço das polícias antes do apogeu da democracia, antes da segunda metade 
de 1970 - se comportavam como "juízes de rua". Para a maioria dos mais jovens, comportamentos que impliquem juízos que penalizem directamente os envolvidos, sejam estes as vítimas ou os agressores, não são parte legítima do seu trabalho. Defendem que a sua "arma é a caneta", o registro, o encaminhar da informação para quem de direito (Durão 2008). Ou seja, estes agentes apenas consideram duas formas de intervenção: uma moralista (tida por amadora) e uma distanciada e discreta (tida por profissional). Todavia, reconhecem e lamentam que a atitude que consideram profissionalizante pareça a todos, incluindo a si mesmos, inevitavelmente pouco interventiva, travada e, por isso, impotente.

Darei apenas um exemplo: o uso do flagrante delito no policiamento de casos de VD. Referi no início deste texto que a abordagem jurídica - a Lei - prevê um entendimento amplo de intervenção policial em situações de "flagrante delito", sempre que justificável e depois devidamente sustentado no auto policial. ${ }^{9}$ Por seu lado, os agentes policiais consideram que o uso que o Judiciário - juízes e magistrados - faz desta figura legal, o flagrante, é extremamente conservador, pois entende que o crime só deve ser punido pelos agentes se directamente testemunhado, quando observado no curso da acção, isto é, visualizado. Crendo saber o que creem os magistrados, os agentes policiais travam, ocasionalmente lembrando trocas de experiências anteriores ou partilhadas sobre idas a tribunal para testemunhar e justificar intervenção em matéria de VD. Afrouxam mesmo em casos como o descrito, que tenderiam a figurar nas classificações formais e nos autos policiais que registram as ocorrências como "casos de risco". Como vários policiais repetiram, tanto na minha direcção como na execução dos casos: "O melhor é não arriscar muito. Nós encaminhamos o processo; os juízes que decidam".

Ficou todavia claro, durante o trabalho de campo, que muitos agentes têm um julgamento moral acerca dos limites que se autoimpõem. Esta é uma das formas de impotência assumidas à qual chamo de impotência resignada. No plano estritamente formal, não há nada que possa se recriminar na atuação dos profissionais. De fato, eles não estão aquém ou além da lei. Ainda assim, a acção é percebida pelos envolvidos, incluindo os próprios, como limitada, verificando-se uma entrada em cena, ainda que difusa, da noção de direitos das vítimas.

Uma outra variação da impotência surgiu em alguns policiais, de modo bem mais pontual e mitigado. Poderia dar muitos exemplos de conversas e resultados das observações. Escolho uma parte dos diários do Marçal, o chefe de uma delegacia em Lisboa que aceitou escrever para nós, para o projeto, notas sobre o seu trabalho. Ele dizia assim: 
Nós damos às pessoas aquelas folhas todas, com muitos direitos mas, na prática, aquilo funciona tudo muito pouco e muito mal. As instituições não estão aqui, tudo se passa mais longe, em gabinetes, fora do aquecimento das coisas, tudo se torna muito relativo, frio, distante, apático e violento. Sinto muitas vezes que o início da queixa é também, muitas vezes, o início de uma escalada da violência sobre as vítimas que todo o sistema policial, judicial e de assistência tende a acentuar mais (Escrito a 05.08.2011, Sexta-feira, no turno das 19h à 01h).

Nas considerações de Marçal, e de uma minoria que pensa como ele, a acção dos agentes de autoridade e da justiça não está à altura de corrigir as violências testemunhadas. Ou seja, a impotência não é moralmente justificável, mas sim um problema em si mesmo. É claramente apontada a intencionalidade de querer "fazer mais" pelas vítimas (responsabilizando os agressores), mas encontrando freios que acabam redundando na mesma impotência. Um desencorajamento, não tanto à partida, na tomada de decisão da agência policial pelos mínimos burocráticos, mas sim no final da linha, em relação aos fracos resultados judiciais após a decisão de atuar em prol dos direitos.

Como seria de esperar, também aqui existem referências às relações mantidas com os juízes, mas num outro sentido. Profissionais como o Marçal creem que, ao vigiarem os limites da acção dos agentes, os juízes circunscrevem o espaço profissional e de autoridade da intervenção dos primeiros e fazem-nos recuar em relação ao que poderia ser uma intervenção mais consentânea com o que deles se espera no plano dos direitos das vítimas. Policiais como ele criticam, por um lado, as formas de judicialização da sociedade e a crença de que a Lei por si só devolveria os direitos às vítimas de VD. E lamentam, muito concretamente, a judicialização da actividade policial, o que faz com que a justiça possa ser promovida sem necessariamente ser acompanhada por segurança.

A reclamação desses agentes passa pelo que consideram ser uma subordinação da autoridade policial ao tempo da justiça, com consequente afastamento entre o Direito e os direitos das vítimas. Nos seus diários, o chefe Marçal narra a forma como certa vez, ao depor em tribunal num caso de VD, foi acusado pelo juiz de abuso de poder por ter escrito nos autos que, na sequência de uma denúncia desencadeada por uma mulher, interpelara o agressor, o cônjuge da mesma, e lhe perguntara sobre a intenção de levar avante as ameaças de morte que fizera à esposa na frente dos filhos. Na sequência da narração, Marçal questionava:

Esta excessiva concentração do poder nos tribunais e no ministério público não estará a servir para diminuir o próprio poder do Estado, para descaracterizar 
toda uma eficácia do poder policial e judicial? Será que as vítimas querem esse poder judicial, independente sim, mas tão distante dos seus sofrimentos e dos seus prejuízos? Penso que não... (Escrito a 20.08.2011 - Sábado, no turno da $01 \mathrm{~h}$ às $07 \mathrm{~h})$.

A esta dinâmica intersubjectiva, que decorre de práticas e reflexões sobre a agência, eu chamo de impotência indignada. Nesse sentido, alguns agentes tentam ampliar, com os meios de que dispõem, a sua acção junto das vítimas, incluindo pela primeira vez contactos com os agressores - elemento evasivo de todo esse processo de reconstrução legal e atuação judicial. Mas por ser previsível a subalternização e até a repreensão moral da acção policial por parte dos magistrados,torna-se mais seguro para todos o recuo a uma acção pelos mínimos burocráticos. Isso leva os agentes a evidenciarem um desconforto: o de que os magistrados e os juízes desconfiam dos policiais, o que em última instância conduz a uma divisão moral do trabalho na justiça, no sistema de segurança pública e justiça criminal, de onde os designados agentes da autoridade, isto é, os policiais, se consideram relativamente excluídos - desautorizados.

A este propósito vale a pena integrar ao artigo uma importante nota de contexto. As duas maiores forças policiais públicas portuguesas - a Polícia de Segurança Pública, conhecida como PSP (uma polícia eminentemente urbana) e a Guarda Nacional Republicana, vulgo GNR (a gendarmerie para as áreas rurais) — são ambas duplamente bicéfalas. As duas maiores forças de segurança respondem tanto ao Ministério da Administração Interna quanto ao Ministério da Justiça. As duas se encarregam da patrulha regular das ruas e do consequente movimento de participações à polícia, registro de autos e tratamento de processos-crime. Isto para delitos com moldura penal até cinco anos de pena de prisão, o que em Portugal representa a grande maioria dos delitos. ${ }^{10}$ É a Polícia Judiciária que se encarrega, actualmente, dos crimes considerados muito graves.

Assim, quando se trata de ordem pública, passeatas nas ruas, gestão do trânsito e outras infrações, as Polícias de competência genérica, PSP e GNR, recebem ordens do Ministério da Administração Interna (são as "forças da ordem"). Quando lidam com crimes que envolvem processos judiciais, reportam-se ao Ministério da Justiça e as suas tarefas passam a ser supervisionadas pelo Ministério Público (passam a "forças da lei"). Tal situação faz com que os agentes de autoridade nas delegacias estejam sempre muito sujeitos não só às pressões dos cidadãos quanto à garantia dos seus direitos e à necessidade de responder a um imenso amontoado de demandas, mas também no sentido de terem de acolher normativas e decisões diversas de 
quem os governa em diferentes momentos e situações. Por isso, os agentes me revelaram muitas vezes: "Há muita gente a mandar na Polícia".

\section{Mulheres vitimizadas e impotentes}

O que se passa do lado das vítimas? No projeto contámos com a colaboração da Associação de Apoio à Vítima (APAV), que nos possibilitou o contato direto e entrevistas em várias sessões com um conjunto de dez mulheres. Embora solicitado, nenhum homem aceitou ser entrevistado. O único critério da selecção dos entrevistados foi terem tido contactos por denúncia de VD com policiais e os seus casos na justiça.

Surpreendentemente, ou talvez não, as mulheres que entrevistámos manifestaram certo prolongamento do sentimento de impotência dos agentes, isto é, na generalidade, quando convidadas a falar da intervenção policial, elas mostraram compreensão pela impotência e pelo recuo dos profissionais. Tal leitura evidencia ao mesmo tempo algum pré-entendimento da subalternização da autoridade dos agentes em face dos magistrados. Mas ao se apresentarem tolerantes, o recuo dessas mesmas polícias ganha em apoio externo, embora desmoralizado, mantendo mais evidente a subalternização descrita pelos agentes no campo da justiça.

Por isso afirmo que a impotência é gerada em mão dupla. Demonstrei até aqui como ela é burocrática e profissionalmente construída, autojustificada. Só que a impotência policial não se limita a si mesma; ela gera formas de incapacitação nas vítimas. Uma pergunta merece então ser colocada: será que esta impotência, manifesta em palavras e gestos, tanto de policiais como de vítimas, implica uma recusa ao direito da expressão emocional das mulheres que reclamam ser vítimas de violência conjugal? Veremos que sim.

Convoco aqui a narrativa de uma das entrevistadas, Maria de Fátima, com 62 anos, empregada doméstica.

Casei-me com ele depois de o meu marido ter morrido. Vivemos quatro anos juntos. Quando me separei, ele vinha quase todos os dias para a porta do meu prédio fazer espetáculo, gritar: "És uma vaca, uma puta, uma ladra, beijaste vagabundos na minha frente, nunca soubeste ser mulher...". Cada vez que ele vinha eu chamava a Polícia. Os agentes chegavam e mandavam-no embora, mas ele depois vinha outra vez. Andei nisto até novembro de 2010, quando ele desapareceu. Depois de o tribunal o chamar anda a monte. Ninguém sabe onde está. No tribunal dizem que não sabem do paradeiro dele, embora vizinhos me tenham dito que já o viram por aqui a rondar [...] Os agentes tomavam conta 
da ocorrência, falavam com ele e mandavam-no embora. Era o que eles me diziam: A gente não pode fazer mais nada... Mas a Polícia para mim era o meu anjo da guarda. [...] Havia alturas em que eu ia diretamente pôr o requerimento ao tribunal, mas chamava a Polícia na mesma. De todas as vezes que ele veio e que eu os chamei, eles vieram. Mas diziam sempre: A gente não pode fazer nada. Eram sempre agentes diferentes, mas já todos sabiam do meu caso. [...] Ele andava sempre com a arma dentro da mala. Dele, medo não tenho e nunca tive. Tenho medo é da arma. Ele disse que ia meter uma bomba na minha casa e que ia tudo pelos ares. Tem-me ameaçado tantas vezes que eu vivo com medo. Chegou a dizer para a própria Polícia: "Qualquer dia venho aqui e rebento com tudo". A Polícia tudo isso escreveu mas, coitados, eles não podem fazer mais nada [Entrevista, 27 de dezembro de 2010, no Gabinete de Apoio à Vítima de Cascais, Portugal, grifos meus].

As impotências dos agentes e das mulheres agredidas não são confundíveis, mas elas interligam-se e se reconfiguram intersubjetivamente por intermédio da acção policial-judicial sobre questões de Direito e de direitos. A impotência de mulheres como Maria de Fátima pode ser definida como uma impotência colaborativa. Algumas formas de impotência mais "duras" foram manifestadas por uma das entrevistadas, que acusou agentes de estarem comprometidos com o seu ex-marido, um poderoso comerciante no local onde residiam. À excepção deste caso, todas as restantes redundaram numa certa tolerância, impotente, em face dos freios manifestos nas acções dos agentes diante de sua queixa de VD. Tal não significa dizer que há uma redução da expectativa, ou afirmar que não se espera algo mais. Espera-se sim, mas sem grande esperança, isto é, sem uma projecção mediada de um futuro que ainda não teve lugar mas está prestes a ser alcançado, como diria Crapanzano (2004).

\section{Conclusões: do Direito aos direitos}

Após uma série de experiências e trocas intersubjectivas revela-se, às mulheres que recorrem aos serviços policiais, que o que os agentes fazem é tão determinante quanto o que consideram não poder fazer. O lamento impotente dos agentes conquista assim a compreensão das próprias vítimas; é reconhecido como estando neles, mas também para além deles. Há um reconhecimento de que este "presente" — o agente policial — é frequentemente um presente de resposta ausente - ausente de autoridade. Esta é parte integrante da gramática da impotência destes serviços após mais de uma década volvida sobre mudanças fundamentais da Lei de VD. 
A impotência e os freios morais da acção não se fixam tanto em indiferença mútua, mas têm outro tipo de consequências. O uso de algum tipo de poder - neste caso acionado pelo sistema de justiça criminal — é tão decisivo como as sucessivas narrativas e práticas de retirada da autoridade policial no ato, que ajudam a gerar um prolongamento da impotência e da vulnerabilidade daqueles que accionam as denúncias. Em sentido mais lato, os direitos daquelas que dirigem as suas denúncias aos agentes são por isso travados por silenciamentos e neutralizações, sendo um deles, talvez o mais notório, o silenciamento do direito à expressão de sofrimentos e violências privados em domínio público. Ou seja, ao chegar às delegacias, muitas vezes imediatamente na sequência das agressões, a expressão do sofrimento e a dor são de novo remetidas para a privacidade e a solidão, provocando até certo ponto o contrário do que a lei e a filosofia subjacente expressam.

Arriscando uma interpretação mais ampla, assim se cria a ausência do sentido de "comunidade política", como diria Judith Butler, que existiria a partir da possibilidade de partilha da dor, do lamento e do luto, a produção de um "nós" em que cada um de nós fala e se expressa por si e por outros que vivem, convivem intersubjetivamente ao lado de nós. Para Butler, silenciar significa a impossibilidade de fazer existir esse nós fora de nós mesmos - a esfera pública na qual o corpo seria pessoal mas também colectivo, onde finalmente todos pudessem estar fisicamente dependentes e fisicamente vulneráveis, uns perante os outros (2004). ${ }^{11}$

Em sentido inverso, os dados da minha observação mostraram que todos participam, voluntária ou involuntariamente, de uma gramática em que violências privadas são percebidas como se fossem direitos públicos; não necessariamente entendidos e performados, no ato do atendimento policial, enquanto tal, enquanto violências. Confirma-se assim, como defendeu Michael Jackson, que as ambiguidades — nas quais a intersubjectividade humana está mergulhada - podem ser exploradas como problemas de conhecimento antropológico (1998:10).

Como se é uma expressão crucial na teoria antropológica, concretamente quando começou a ser ensaiado um ajuste de contas com o estrutural funcionalismo britânico, gerando-se novas formas de pensamento. Edmund Leach é um dos antropólogos que encabeçam essa passagem, do lado de dentro, nomeadamente através da obra Political systems of Highland Burma (1964 [1954]), criando uma teoria a respeito da relação entre fatos empíricos e generalizações na antropologia social. O autor repensou os rituais já não a la Durkheim, como poder do colectivo sobre o "indivíduo", impondo-se em suas regras e scripts, mas sim nos momentos em que pessoas e grupos procedem como se estivessem em harmonia. Leach foi dos primeiros a colocar 
em causa o pressuposto de equilíbrio dos "sistemas sociais". Defendia que as inconsistências e as ambiguidades não tinham lugar nas monografias da antropologia social britânica, havendo manifesta dificuldade em lidar com a mudança e o devir. Leach reconheceu no equilíbrio um recurso metodológico, mas não um fim da análise antropológica e demonstrou como os ideais de vida política - a hierarquia feudal do sistema chan e o anarquismo igualitário do tipo gumlao - são dinamizados num terceiro, que resulta da sua leitura antropológica, o gumsa.

Feito o paralelo espistêmico, quando digo que as violências privadas são percebidas como se fossem direitos públicos, no caso que aqui trato, refiro-me a algo concreto. Considero certa necessidade de operar no trabalho policial através de ritualizações burocráticas que convivem de fato com moralidades intersubjectivas desafiadoras e contraditórias. Não se trata de simulacro, cinismo ou mesmo de indiferença, como é mais comum se esperar dos estudos sobre burocracias policiais. ${ }^{12}$

Neste texto fica evidente que não existe propriamente concordância ou colaboração social para que determinados "sistemas" - como seja a designada justiça criminal portuguesa - funcionem ou se revelem disfuncionais em sua ação quotidiana. Essa reflexão é do plano da intensão e não da prática empírica. A questão é que elas operam como se estivessem em equilíbrio funcional. Importante é reconhecer que as várias modalidades da ação — incluindo as impotências — se constituem como parte integrante do processo de policiar a violência doméstica.

Será esta uma história do Direito à custa dos direitos? É inquestionável que o Direito cria os canais para a expressão pública de direitos privados. A política da vita activa nas sociedades contemporâneas depende e alicerçase em boa medida na letra da lei e sua constituição histórica, assim como na história de Constituições. Todavia, ao se gerarem acções impotentes, gramaticalmente organizadas, cria-se espaço para recuos, também eles sistemáticos, dos direitos, remetidos para um certo tipo de silenciamento e subjectivismo da dor. Ou seja, tudo se passa como se o sujeito público - a Vítima - fosse um fim abstracto em si mesmo e não um ponto de partida, como outros, para a reflexão sobre a acção do Direito em matéria de direitos.

As relações intersubjectivas neste campo genérico do que se convencionou denominar VD - e em seus desdobramentos semânticos como "violência de género", "violência contra a mulher", "violência contra a pessoa humana", "crimes de ódio"etc. — são atravessadas precisamente por esse aglomerado de intervenções políticas, jurídicas e judiciais sobre conflitos considerados moralmente intoleráveis. Quer dizer que os vários "nativos" — que nunca foram passivos na relação de conhecimento que connosco estabelecem — são 
ativamente atravessados, como nós, aliás, por alguma forma de julgamento civil e do dever de pensar e de agir a favor de direitos. Ou seja, neste contexto, somos todos sujeitos morais em presença, no qual as moralidades de uns interferem na moralidade de outros, de modo intersubjectivo e relacional. Creio que no presente - em sociedades tão mediadas por burocracias como são aquelas em que vivemos - o encontro por intermédio dos serviços de segurança pública em prol da justiça é particularmente central para entendermos dimensões sensíveis da vida humana. ${ }^{13}$

Não digo que não seja importante auditar o bom e o mau uso da lei, a arbitrariedade e a discricionariedade policiais. Mas muito, e muito do que é relevante na vida como na justiça, não se limita ao domínio da avaliação técnica de eficácias, que opera por dentro do idioma da lei e esquece de escrutinar os resultados sociais de seus usos. Embora canalisadas entre si, segurança e justiça podem não significar o mesmo do lado daqueles que recorrem aos serviços policiais. Este é um dado para pensarmos com mais acuidade no futuro.

Além disso, é preciso lembrar, como defende Guita Grin Debert (2006), que "violência" não é apenas um ato social em si, entre sujeitos — e, no entender de Butler, parte da vulnerabilidade original da vida colectiva humana mas algo que se configura e reconfigura em texturas políticas, judiciais, policiais-institucionais e, diria eu, morais. Nesse sentido, Debert analisou detalhadamente os limites e os dilemas que atravessam a justiça em prática, com base em pesquisas desenvolvidas em delegacias de defesa da mulher no estado de São Paulo (Brasil). Para a autora, enquanto as categorias "violência de género", e outras, permitiram repolitizar e ressignificar questões de justiça e direitos, de acordo com os nossos dados, para o caso português, a maior universalidade dos termos da "violência doméstica" não necessariamente resulta num movimento similar. ${ }^{14}$ Como foi demonstrado neste texto, mesmo com grandes mudanças legais, mantém-se uma hesitação intersubejtiva nas vítimas entrevistadas quanto à noção de que de fato possuem o direito à segurança, à assistência e à justiça. Para simplificar muito a questão, podemos perceber que em Portugal há um intervalo que merece ser antropologicamente conhecido entre o que é do plano do Direito e o que se passa no plano dos direitos.

O ponto em comum nestes trabalhos está na chamada de atenção para o fato de que a relação de pesquisa que inclui agenciamentos do Estado e suas recepções se complexificou muito e que, por isso mesmo, uma antropologia crítica não pode mais reduzir-se à leitura linear que avalia a capacidade demonstrada de punição e de reparação dos agentes policiais e da justiça em face das vítimas "indefesas". A capacidade de produção de vita activa é infindável. A génese do elemento político pode agora ser encontrada nas expressões de 
impotência de sujeitos que esperam uma mediação diferente daquela que recebem ou que receberam ao se dirigirem às delegacias, mas encontrando nos freios do Estado a sua própria incapacidade de formular a exigência.

Por fim, ao insistir num prisma antropológico, estamos a evitar a mimetização dos procedimentos intelectuais das chamadas "ciências normativas" - do Direito. A este propósito, vale a pena terminar o texto com uma petite histoire do trabalho de campo. Certo dia, no âmbito do nosso projeto, entrevistei o ministro da Administração Interna, Rui Pereira, prestigiado jurista e académico, responsável pela revisão do Código Penal Português e grande defensor das reformas recentes introduzidas pelas leis da VD nas quais colaborou. No geral, ele reiterou os dados que vieram a fazer parte do meu argumento. Defendeu tratar-se de uma lei a favor da vítima, sem reflectir muito o que fazer com o agressor, executada dominantemente pelos magistrados e com uma participação controlada dos policiais.

Um episódio particular mereceu todavia a minha atenção. No final do encontro, já na porta de saída, o ministro não resistiu a lembrar considerações do seu tempo de estudante. Nos anos 1970, na tradicional e secular universidade de Coimbra, onde ele se formara, professores e alunos diziam, "com certa ironia", que as ciências sociais eram as "ciências do oculto". Não eram "verdadeira ciência" (palavras suas). É preciso entender que o campo do Direito em Portugal relançou as humanidades no período democrático pós-revolucionário, depois de 1974. As ciências sociais foram criando o seu espaço paulatinamente e em núcleos muito mais restritos. $\mathrm{Na}$ altura, respondendo com uma provocação à provocação, afirmei que estava disposta a aceitar aquela definição. Disse que me parecia que o interesse da antropologia, que eu e outros fazíamos, passava por tornar o "oculto" uma dimensão positiva do saber, algo de que até o Direito faria parte.

Presumo que hoje muitos agentes da autoridade, mais os indignados do que os resignados, sejam seduzidos pela leitura de textos como este. $\mathrm{Na}$ verdade, todos eles têm as suas ideias sobre o que não vai bem na Polícia, nos seus próprios gestos, mas ninguém sabe ao certo como lhe fazer frente. Os canais da impotência não são fáceis de decifrar. 


\section{Notas}

${ }^{1}$ A este respeito, ler, por exemplo, os trabalhos de Dias (2010); Gomes (2011); Mawby (1999); Richards, Letchford e Stratton (2008).

${ }^{2}$ Uma entrevista conduzida em 2011 com a falecida Teresa Rosmaninho, uma feminista promotora de mudanças neste campo nas forças policiais, foi reveladora. Quando convidada a analisar a lei, ela foi peremptória: "A questão da violência doméstica abarca a violência de género, não é apenas dirigida à mulher, mas a todos. Sobre isso todos [juristas, magistrados, parlamentares e militantes feministas] estivemos sempre de acordo" (Entrevista conduzida em 10.11.2010, Porto).

${ }^{3}$ Para facilitar a leitura do texto em contexto brasileiro, usamos o termo delegacia para nos referirmos a esquadras de polícia.

${ }^{4}$ Para se ter uma ideia do reduzido número de mulheres policiais no universo das delegacias, de acordo com o último Balanço Social da Polícia de Segurança Pública, relativo ao ano de 2011, a porcentagem de agentes femininas, no conjunto dos homens na mesma posição hierárquica, era de $7,03 \%$ e as mulheres chefes, no conjunto dos homens na mesma situação, era de 9,18\%. Agentes e chefes tanto podem ocupar cargos operacionais nas delegacias, como podem estar em postos administrativos, o que acontece com muita frequência no caso das mulheres, sobretudo quando passam a ser mães. Curiosamente, no caso português, o número de mulheres entre o estatuto oficial tem um percentual superior, chegando a 10,96\% do conjunto dos homens com este estatuto. Mas esses oficiais têm um contacto muito mais indirecto e superficial com os cidadãos.

${ }^{5}$ Women in police stations: violent crime and gender relationships / Mulheres nas esquadras: crimes de violência e relações de género (FCT PIHM/VG/0131/2008) foi financiado pela Fundação para a Ciência e Tecnologia em Portugal, ao abrigo de protocolo estabelecido com a Secretaria de Estado da Igualdade, na área científica da Violência de Género. O projeto decorreu entre Setembro de 2009 e Fevereiro de 2012, no âmbito das atividades científicas do Instituto de Ciências Sociais da Universidade de Lisboa, e foi executado com a colaboração de Pedro Moura Ferreira (sociólogo do ICS/UL, Lisboa) e de Marcio Darck (mestrando em criminologia na FDUP, Porto). O referido projeto originou um outro, que atualmente coordeno, e que tem por título Urban policing in Portugal: unveiling police(men) histories, 1860-1960/ Polícia urbana em Portugal: história da polícia e histórias de polícias, 1860-1960 (PTDC/ HIS-HIS/115531/2009).

${ }^{6}$ Ver, em particular, as obras de Michael Jackson, Minima ethnographica: intersubjectivity and the anthropological project (1998) e Lifeworlds. Essays in existential anthropology (2012). De Alessandro Duranti destacaria "The relevance of Husserl's theory to language socialization" (2009) e, muito particularmente, "Husserl, intersubjectivity and anthropology" (2010).

${ }^{7}$ Agradeço a Maria Claudia Coelho as conversas que tivemos a este respeito e que me levaram a reflectir sobre esta dimensão na pesquisa que aqui tomo para análise. 
${ }^{8}$ Uma referência pertinente para reflexões sobre morais e moralidades relacionais e situacionais é a recente obra O bairro fala: conflitos, moralidades e justiça no conurbano bonaerense, de Lucia Eilbaum (2012).

${ }^{9}$ De acordo com o art. ${ }^{\circ} 256^{\circ}$, da Lei n. ${ }^{\circ}$ 59/98, de 25 de Agosto do Código de Processo Penal português, prevê-se detenção quando o autor for, logo após o crime, perseguido por qualquer um ou encontrado com objectos ou sinais que mostrem claramente que acabou de o cometer ou dele participar. Esta lei trata assim de actualidade, não de visibilidade da infracção pois não é necessário que os agentes da autoridade "presenciem" o crime. Especificamente para os casos de violência doméstica, o n. ${ }^{0} 3$ do artigo $30 .^{\circ}$ da Lei n. ${ }^{\circ}$ 112/2009, de 16 de Setembro, que estabelece o regime jurídico aplicável à prevenção da violência doméstica, à protecção e à assistência das suas vítimas, prevê que as autoridades policiais podem também ordenar a detenção fora de flagrante delito (Agradeço a Marcio Darck estas notas de análise legal).

${ }^{10}$ Para se ter uma ideia, os cinco tipos de crimes mais participados às autoridades policias entre 2011-12 foram o furto em veículo motorizado; ofensa à integridade física voluntária simples; condução de veículo com taxa de álcool ilegal; furto em residência com arrombamento ou chaves falsas; violência doméstica contra cônjuge ou análogos. A criminalidade designada por violenta, com casos de roubo e atentado à vida, é pouco expressiva nas tendências da criminalidade analisadas em Portugal nas últimas décadas. Entre os 14 países da EU, o país figura no penúltimo lugar, com um dos menores números de crimes participados às autoridades: 39 para cada 1.000 habitantes (cf. RASI 2012).

${ }^{11}$ No limite, o que a autora propõe é que se viva essa vulnerabilidade "comum" original e corpórea como a base para um novo humanitarismo. Deste ponto de vista, a comunidade política não tem existência ou inexistência, ela é criada assim como o é a anticomunidade política.

${ }^{12}$ A este propósito, sem querer ser exaustiva, podem ler-se alguns textos clássicos e compilações sobre o que ficou conhecido como "cultura policial" e a sua relação com o simulacro e o cinismo (Monjardet 1996; Reiner 1985; Skolnick 2005; Waddington 2005; Westmarland 2008).

${ }^{13}$ A este respeito vale a pena ler as contribuições recentes de Pina Cabral (2011) e Durão e Lopes (2011) sobre como repensar as instituições na antropologia contemporânea.

${ }^{14}$ Diferente do que acontece em Portugal, vários trabalhos no Brasil apresentam reflexões sobre a importância das lutas feministas e por direitos de género nas conquistas legais e nas mudanças impressas por um atendimento policial preferencial (Corrêa 1981, 1983; Debert et al 2006; Santos 2005, 2010; Soares 1999). O movimento foi classificado como de "politização da justiça". Todavia, mais recentemente, autoras vêm defendendo que se observa no Brasil uma tendência para a "reprivatização da justiça" que coloca a tônica na conservação da família e não tanto na protecção de direitos associados à agenda igualitária que levou à criação das delegacias especiais (Debert 2006). 


\section{Referências bibliográficas}

ARENDT, Hannah. 1991[1958]. A condição humana. São Paulo: Forense Universitária.

BUTLER, Judith. 2004. "Violence, mourning, politics". In: Precarious life. The powers of mourning and violence. London \& New York: Verso. pp. 19-49.

CARNEIRO DA CUNHA, Manuela \& ALMEIDA, M. B. 2009. "Populações tradicionais e conservação ambiental". In: M. Carneiro da Cunha (org.), Cultura com aspas e outros ensaios. São Paulo: Cosac Naify. pp. 277-300.

CORRÊA, Mariza. 1981. Os crimes da paixão. São Paulo: Brasiliense.

- 1983. Morte em família: representações jurídicas e papéis sexuais. Rio de Janeiro: Graal.

CRAPANZANO, Vincent. 2004. Imaginative horizons - an essay in literary-philosophical anthropology. Chicago \& London: The University of Chicago Press.

DEBERT, Guita G.; GREGORI, Maria F. \& PISCITELLI, Adriana (eds.). 2006. Gênero e distribuição da justiça: as delegacias de defesa da mulher e a construção das diferenças. Campinas: Pagu - Núcleo de Estudos de Género/ Editora da Unicamp.

DEBERT, Guita Grin. 2006. "Conflitos éticos nas Delegacias de Defesa da Mulher". In: G. G. Debert; M. F. Gregory \&A. Piscitelli (eds.), Gênero e distribuição da justiça: as delegacias de defesa da mulher e a construção das diferenças. Campinas: Pagu - Núcleo de Estudos de Género/ Editora da Unicamp. pp. 57-88.

DIAS, Isabel. 2010. "Violência doméstica e justiça: respostas e desafios". Revista da Faculdade de Letras: Sociologia, 20:245262. Disponível em: http://repositorioaberto.up.pt/handle/10216/55996. Acesso em 20/06/2013.
DONZELOT, Jacques. 2005 [1977]. La police des familles. Paris: Les Editions de Minuit.

DURANTI, Alessandro. 2009. "The relevance of Husserl's theory to language socialization". Journal of Linguistic Anthropology, 19(2):205-226. . 2010. "Husserl, intersubjectivity and anthropology. Anthropological Theory, 10(1):1-20.

DURÃO, Susana \& LOPES, Daniel Seabra. 2011. "Introduction: institutions are us?" Social Anthropology/ Anthropologie sociale - Rethinking Institutions (Special Issue), 19(4): 363-377. .2012. "Policiamento de proximidade em Portugal: limites de uma metáfora mobilizadora". In: S. Durão \& M. Darck (orgs.), Polícia, segurança e ordem pública. Perspectivas portuguesas e brasileiras. Lisboa: Imprensa de Ciências Sociais. pp. 101-134. . \& DARCK, Marcio. 2013. "Investigação policial em crimes de violência doméstica: possibilidades e recuos". In: Susana Costa \& Helena Machado (orgs.), A ciência na luta contra o crime: potencialidades e limites. Coimbra: Editora Humus. pp. 119-141.

DURHAM, Eunice Ribeiro. 2004."A pesquisa antropológica com populações urbana". In: E. Durham (Apresentação: Omar. R. Thomaz; Prefácio: Peter Fry), A dinâmica da cultura. São Paulo: CosacNaify. pp. 357-376.

EILBAUM, Lucía. 2012. O bairro fala: conflitos, moralidades e justiça no conurbano bonaerense. São Paulo: Hucitec/ANPOCS.

ELIACHEFF, Caroline \& LAVIÈRE, Daniel Soulez. 2007. Le temps des victimes. Paris: Editions Albin Michel. 
EVANS-PRITCHARD, E. E. 1962. Essays in social anthropology. London: Faber \& Faber

FABIAN, Johannes. 1971. "Language, history and anthropology". Philosophy of the Social Sciences, 1:19-47.

GEERTZ, Clifford. 1989 [1973]. A interpretação das culturas. Rio de Janeiro: Livros Técnicos e Científicos Editora.

GOMES, Conceição. 2011.Os atrasos da justiça. Lisboa: Fundação Francisco Manuel dos Santos.

GONÇALVES, José Reginaldo Santos (org.). 2011. "Sobre a alegoria etnográfica". In: James Clifford, A experiência etnográfica. Antropologia e literatura no século XX. Rio de Janeiro: Editora UFRJ. pp. 59-92.

HERZFELD, Michael. 1992. The Social Production of Indifference. Exploring the Symbolic Roots of Western Bureaucracy. New York. Oxford: Berg Publishers.

INGOLD, Tim. 1989. "The concept of society is theoretically obsolete". In:__ (ed.), Key debates in anthropology. London \& New York: Routledge. pp 57-82.

JACKSON, Michael.2012. Lifeworlds. Essays in existential anthropology. Chicago: The University of Chicago Press. - 1998. Minima ethnographica: intersubjectivity and the anthropological project. Chicago: Chicago University Press.

LEACH, Edmund.1964 [1954]. Political systems of Highland Burma. A study of kachin social structure. London: The London School of Economics and Poltical Science/ C. Bell and Sons.

LONG, Nocholas J. \& MOORE, Henrietta L. (eds). 2013. Sociality: new directions. New York \& Oxford: Berghahn Books.

MALINOWSKI, Bronislaw. 2003. Crime e costume na sociedade selvagem. Brasília: Editora daUnB.
MAWBY, R.I. 1999. "Police services for crime victims". In: __. (ed.), Policing across the world: issues for the twenty-first century. London: Routledge. pp. 187-203.

MONJARDET, Dominique. 1996. "Règles, procédures et transgressions dans le travail policier".In: Jacques Girin \& Michèle Grosjean (eds.), La transgression des règles au travail. Paris: L'Harmattan. pp. 83-94.

NADER, Laura. 2011. "Ethnography as theory". HAU: Journal of Ethnographic Theory, 1(1):211-219.

PINA-CABRAL, João de. 2011. "Afterword: what is an institution?". Social Anthropology/Anthropologie sociale Rethinking Institutions (Special Issue), 19(4):477-494.

REINER, Robert. 1985. The politics of the police. Sussex: Wheatsheaf Books \& Harvest Press.

RICHARDS, L., LETCHFORD, S., \& STRATTON, S. 2008. Policing domestic violence. New York: Oxford University Press.

SANTOS, Cecília MacDowell. 2005. Women's police stations: gender, violence, and justice in São Paulo, Brazil. New York: Palgrave Macmillan.

- 2010. "Da delegacia da mulher à Lei Maria da Penha: absorção/tradução de demandas feministas pelo Estado". Revista Crítica de Ciências Sociais, 89:153-170.

SARTI, Cynthia A. 2009. 'Corpo, violência e saúde: a produção da vítima', Sexualidad, Salud y Sociedad. Revista Latinoamericana, 1:89-103.

SKOLNICK, Jerome. 2005. "A sketch of the policeman's 'working personality'". In: Tim Newburn (ed.), Policing. Key readings. London \& New York: Willan Publishing. pp. 264-279.

SOARES, Barbara Musumeci. 1999. Mulheres invisíveis: violência conjugal e as novas políticas de segurança. Rio de Janeiro: Editora Record. 
STRATHERN, Marilyn. 2007.O gênero da dádiva. Campinas: Editora da Unicamp.

WADDINGTON, P. A. J. 2005. "Police (canteen) sub-culture: an appreciation". In: Tim Newburn (ed.), Policing. Key readings. London \& New York: Willan Publishing. pp. 364-386.

WESTMARLAND, Louise. 2008. "Police cultures". In: Tim Newburn (ed.), Hanbook of policing. London \& New York: Willan Publishing. pp. 253-280.

ZIGON, Jarrett. 2008. Morality: an anthropological perspective. Oxford: Berg Publishers.

\section{Outros documentos}

DGAI. 2011. Violência doméstica: análise das ocorrências participadas às Forças de Segurança durante o ano de 2010. Direcção Geral da Administração Interna. Disponível em: http://www. dgai.mai.gov.pt/cms/files/conteudos/ VD_4 Maio 2011_rev.pdf. Acesso em a 20/06/2013.

DGAI. (2011a). Violência doméstica 2010: ocorrências participadas às Forças de segurança. Disponível em: http://www. dgai.mai.gov.pt/cms/files/conteudos/ VD_RelatorioAnual_2010_2_5_2011. pdf Acesso em 20/06/2013.

RASI. 2012. Relatório anual de segurança interna. Sistema de Segurança Interna, Gabinete do Secretário Geral. Disponível em:http://www.portugal. gov.pt/media/904058/20130327_ RASI\%202012_vers\%C3\%A3o\%20final. pdf Acesso em 20/06/2013. 


\section{Resumo}

O texto discorre sobre contextos de relação entre agentes policiais e mulheres que reclamam para si o estatuto de vítimas de violência doméstica em Portugal. O artigo propõe uma leitura do Direito e de direitos à luz de teorias da intersubjectividade humana. Seguindo este caminho interpretativo, sobressai a construção social de uma gramática de impotências e reprivatizações da dor que, com variações significativas, atravessam os encontros.

Palavras-chave Policiamento, Violência Doméstica, Direitos, Impotência, Intersubjetividade, Socialidade.

\section{Abstract}

This article examines the relationship between police officers and women who claim the status of victims of domestic violence in Portugal. The text proposes a reading of Law and rights in light of theories of human intersubjectivity. This line of interpretation highlights the social construction of a grammar of disempowerment and the re-privatization of pain, with significant variation between distinct encounters.

Key words Policing, Domestic Violence, Rights, Disempowerment, Intersubjectivity, Sociality. 